\title{
UV Photocatalytic Degradation of Commercial Naphthenic Acid Using $\mathrm{TiO}_{2}$-Zeolite Composites
}

\author{
Kennedy K. Kalebaila*, Craig Fairbridge \\ Natural Resources Canada, CanmetENERGY, Devon, Canada \\ Email: ${ }^{*}$ kkalebai@gmail.com, craig.fairbridge@nrcan.gc.ca
}

Received 16 July 2014; revised 12 August 2014; accepted 5 September 2014

Copyright (C) 2014 by authors and Scientific Research Publishing Inc.

This work is licensed under the Creative Commons Attribution International License (CC BY). http://creativecommons.org/licenses/by/4.0/

c) (i) Open Access

\section{Abstract}

The presence of naphthenic acids in oil sand products and process streams is the cause of toxicity to aquatic life and corrosion. The removal of organic acids from tailings pond water reduces the negative impact on marine life. The ultra-violet (UV) photocatalytic reduction of commercial naphthenic acid in water using $\mathrm{TiO}_{2}$-zeolitecomposites showed a significant decrease in the concentration of naphthenic acid, accompanied by an increase in carbon dioxide formation; the presence of carbon dioxide signifies degradation of the naphthenic acids. Mixtures of the acid and photocatalyst kept in the dark did not show any concentration changes. The extent of naphthenic acid reduction by UV light was verified by the reduction in total acidity. The total acidity values of mixtures of the acid and $\mathrm{TiO}_{2}$-zeoliteexposed to $\mathrm{UV}$ decreased by $31 \%$ compared to mixtures kept in the dark. A reduction in total acidity may lead to a decrease in the toxicity of naphthenic acid contaminated water.

\section{Keywords}

Naphthenic Acid Conversion, GC-MS, TAN, Diffuse Reflectance, $\mathrm{TiO}_{2}$-Zeolite

\section{Introduction}

Naphthenic acids (NAs) are found naturally in crude oils or oil sands bitumen and are an oxidative product of petroleum hydrocarbons. The oil sand reserves are highly-biodegraded petroleum that are viscous and tar-like and are often produced by steam assisted gravity drainage. Surface mining is also employed to recover bitumen involving an alkaline hot water extraction process. After the extraction process, the tailings consisting of resi-

"Corresponding author.

How to cite this paper: Kalebaila, K.K. and Fairbridge, C. (2014) UV Photocatalytic Degradation of Commercial Naphthenic Acid Using $\mathrm{TiO}_{2}$-Zeolite Composites. Journal of Water Resource and Protection, 6, 1198-1206.

http://dx.doi.org/10.4236/jwarp.2014.612109 
dual bitumen and slurry of sand, silt, clay, are retained in ponds to permit sedimentation of solids resulting in overflowing water called oil sand process water. Naphthenic acid contaminated water is thought to be toxic to aquatic life by interfering with gas exchange and metabolic processes in plants and fish. [1] [2] The availability of carboxylic groups in the NA structure enhances pipeline and machinery corrosion by reacting with metal ions. The amount of NA in tailings pond water is determined by the total acid number or TAN. The higher the TAN value is, the higher the amount of naphthenic acid and the poorer the tailings water are.

Among the various methods of reducing the concentration and toxicity of naphthenic acids in contaminated water, chemical treatment involving use of oxidants such as ozone, permanganate, and chlorine has been proven but the high operating costs coupled with production of hazardous by-products is problematic. Compared to chemical processing, a low cost technology is bioremediation which relies on the use of microorganisms to remove organic wastes. It has been shown that microorganisms found in some local tailing ponds can metabolize surrogate NAs, but the biodegradation occurred at very slow rates [3]-[5]. The development of membrane bioreactors has enhanced bioremediation processes compared to traditional biological treatments, [6] nonetheless, research in this field is ongoing as it is not yet clear whether bioremediation is effective in conventional oilfield water.

Photocatalytic oxidation is emerging as an innovative approach for treatment of organic pollutants including NAs. It has been reported that UV-B (280 - $315 \mathrm{~nm})$ and UV-C $(200-280 \mathrm{~nm})$ wavelengths are suitable for most waste water treatments, with the optimal wavelength at $254 \mathrm{~nm}$ ideal for remediation of naphthenic acids, where the photocatalysts are either immersed in the contaminated water as a slurry or used in a fixed-bed reactor [7]-[9]. Photocatalytic degradation rates are strongly dependent on the efficiency of adsorption of pollutants on the catalysts, thus, good photocatalyst design is essential for effective adsorption and subsequent degradation of naphthenic acids. Structure modification of the parent $\mathrm{TiO}_{2}$ includes improvement in surface area by incorporating high surface area matrices such as silica $\left(\mathrm{SiO}_{2}\right)$ and zeolites, addition of chelating agents to trap pollutants, and addition of ions to increase visible light absorption [10] [11]. In this work, the photoreduction of a complex commercial naphthenic acid in water using UV-light in the presence of $\mathrm{TiO}_{2}$ prepared in a zeolite matrix was investigated. Any compositional and/or concentration changes in naphthenic acid before and after UV irradiation were followed by GC-MS with electron impact mode.

\section{Materials Section}

The as-prepared $\mathrm{TiO}_{2}$-zeolitecomposites $\left(\mathrm{Z}-\mathrm{TiO}_{2}\right)$ were prepared by wet impregnation method as described in the literature [12] [13]. About $32 \mathrm{~mL}$ of titanium isopropoxide, $\mathrm{Ti}\left(\mathrm{O}^{\mathrm{i}} \mathrm{Pr}\right)_{4}$ and $7 \mathrm{~mL}$ of acetyl acetone were dissolved in a mixture of $100 \mathrm{~mL}$ of isopropyl alcohol and $6 \mathrm{~mL}$ of water. Then $10 \mathrm{~g}$ of commercial zeolite CBV780 (Zeolyst) was added to the solution and left to stir for 12 hours at room temperature. The mixture was then heated to $120^{\circ} \mathrm{C}$ in an Isotemp Muffle Furnace 750 Series (Fisher Scientific), leading to formation of a gelatinous product and the temperature maintained for 8 hours until the product was dry. The dried composites denoted as $\mathrm{Z}-\mathrm{TiO}_{2}$ were finally annealed at $500^{\circ} \mathrm{C}$ for 2 hours and subsequently sieved to 46 - 60 final mesh size.

The complex naphthenic acid was purchased from Sigma-Aldrich and used without further purification. The physical properties of the naphthenic acid included a density of $0.92 \mathrm{~g} / \mathrm{mL}$, solubility in water of $0.05 \mathrm{~g} / \mathrm{L}$ and boiling point range of $106^{\circ} \mathrm{C}-334^{\circ} \mathrm{C}$. For studies, the naphthenic acid was diluted by dissolving $2.07 \mathrm{~mL}$ of acid in $600 \mathrm{~mL}$ water and $200 \mathrm{~mL}$ methanol resulting in a turbid mixture with a final concentration of 0.25 weight\%.

\section{Results and Discussion}

Surface Area and Pore Sizes: The surface area, pore sizes and volumes were determined by the BET (Brunauer, Emmett, and Teller) and BJH (Barrett, Joyner, and Halenda) isotherm models using the ASAP 2020 software on the Micromeritics 2020 physisorption analyzer. The analysis were performed using nitrogen gas as the adsorbate at $-196^{\circ} \mathrm{C}$. Samples were initially degassed at $350^{\circ} \mathrm{C}$ for 1 hour and then at $110^{\circ} \mathrm{C}$ for 4 hours under vacuum in order to remove any adsorbed contaminants from the surface. The BET surface area and the BJH pore sizes and volumes (desorption) of the calcined samples were determined in the pressure ranges of $0.05-0.3$ and 0.5 - 1.0, respectively, producing a type IV isotherm (Figure 1) [14]. The surface area of the commercial zeolite $\left(780 \mathrm{~m}^{2} / \mathrm{g}\right)$ decreases upon addition of $\mathrm{TiO}_{2}$ to $619 \mathrm{~m}^{2} / \mathrm{g}$ while the average pore diameter increased $(4.6 \mathrm{~nm})$ compared to the microporous zeolites (Table 1). Conversely, addition of zeolite to $\mathrm{TiO}_{2}$ increased the surface area compared to $50 \mathrm{~m}^{2} / \mathrm{g}$ of commercial $\mathrm{TiO}_{2}$. 


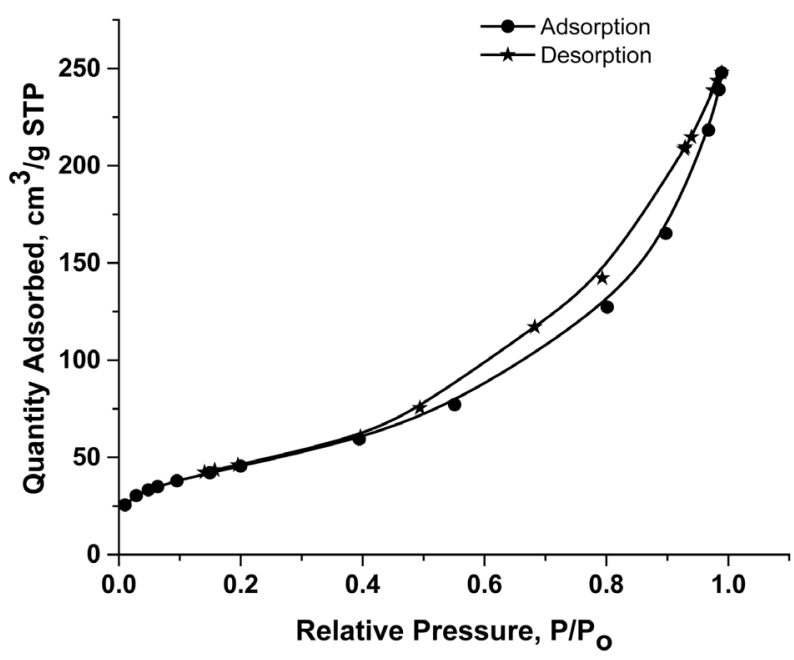

Figure 1. Nitrogen adsorption/desorption isotherms of $\mathrm{Z}-\mathrm{TiO}_{2}$ at $-196^{\circ} \mathrm{C}$.

Table 1. Surface area, pore sizes and pores volumes of $\mathrm{Z}-\mathrm{TiO}_{2}$ and commercial solids.

\begin{tabular}{cccc}
\hline Sample ID & Surface Area, $\mathrm{m}^{2} / \mathrm{g}$ & Pore Diameter, $\mathrm{nm}$ & Pore Volume, $\mathrm{cm}^{3} / \mathrm{g}$ \\
\hline $\mathrm{HY}(\mathrm{CBV} 780)$ & 780 & $<2$ & $0.45-0.48$ \\
$\mathrm{Z}-\mathrm{TiO}_{2}$ & 619 & 4.6 & 0.61 \\
$\mathrm{TiO}_{2}-\mathrm{P} 25$ & $<65$ & 18 & 0.25 \\
\hline
\end{tabular}

Diffuse Reflectance UV-Vis Spectroscopy: The light absorbing properties were determined using UV-VIS diffuse reflectance spectroscopy on a PerkinElmer spectrometer Lambda 45 calibrated for $0 \%$ and $100 \%$ transmission with a $\mathrm{BaSO}_{4}$ standard. The band-gap energies were estimated using $\mathrm{E}=\mathrm{hc} / \lambda=1240 / \lambda$, where $\mathrm{h}$ is Planck's constant, $\mathrm{c}$ is speed of light and; $\lambda$ is the absorption onset wavelength. The onset wavelength was determined by extrapolating the rise in \% reflectance versus the baseline (Figure 2). The results show that $\mathrm{Z}-\mathrm{TiO}_{2}$ has a distinctive UV absorption similar to commercial $\mathrm{TiO}_{2}-\mathrm{P} 25$ at $367 \mathrm{~nm}$. In contrast, UV spectrum of the zeolite could not be determined since the $\mathrm{Al}_{2} \mathrm{O}_{3}$ and $\mathrm{SiO}_{2}$ components in the zeolite have very high band-gap energies in excess of $7 \mathrm{eV}(177 \mathrm{~nm})$ that exceed the instrument range [15].

Diffuse Reflectance Infrared Fourier Transform Spectroscopy (DRIFTS): DRIFTS spectra were recorded on a Bruker Tensor 27 spectrometer using liquid nitrogen cooled HgCdTe detector and OPUS version 6 software. The samples were prepared using $\mathrm{KBr}$ as the background and loaded into a sealable reaction chamber inside a praying mantis (Harrick Scientific). The diffuse reflectance infrared spectra (Figure 3) of $\mathrm{TiO}_{2}-\mathrm{P} 25$, zeolite CBV 780 and as-prepared composite $\left(\mathrm{Z}-\mathrm{TiO}_{2}\right)$ showed a small sharp peak at $3737 \mathrm{~cm}^{-1}$ attributed to terminal $\mathrm{OH}$ groups on $\mathrm{Al}-\mathrm{OH}, \mathrm{Si}-\mathrm{OH}$ in the zeolite and Ti-OH from Degussa P25. Coordinated water molecules $(\mathrm{H}-\mathrm{O}-\mathrm{H})$ exhibit a broad peak centered around $3300 \mathrm{~cm}^{-1}$ while the peak at $1622 \mathrm{~cm}^{-1}$ is due to isolated $\mathrm{OH}$ groups on the solid surface [16]. The Z- $\mathrm{TiO}_{2}$ composite show nearly all features of pure zeolite containing several peaks from $2003 \mathrm{~cm}^{-1}$ to $775 \mathrm{~cm}^{-1}$. Although, most $\mathrm{TiO}_{2}$ vibrational features are masked by the strong zeolite vibrations in the IR spectra, UV diffuse reflectance data of $\mathrm{Z}-\mathrm{TiO}_{2}$ confirmed the presence of $\mathrm{TiO}_{2}$ from the absorption at 338 $\mathrm{nm}$.

Photocatalysis Reactions: About $150 \mathrm{mg}$ of the powdered catalyst and $100 \mathrm{~mL}$ of stock solution of NA were placed in a cylindrical glass reactor of a total volume of $405 \mathrm{~mL}$. The mixture was kept at $25^{\circ} \mathrm{C}$ using a Thermo Fisher Temperature bath under constant stirring with a magnetic stir bar during the course of the reactions. Initially, the catalyst/NA mixtures were kept in the dark up to 48 hours and then exposed to UV light using a Newport Oriel $1000 \mathrm{~W}$ high pressure Hg(Xe) lamp fitted with a 280 - $400 \mathrm{~nm}$ beam turning dichroic mirror (Figure 4). Headspace aliquots from dark (control) and UV light were manually injected into a GC-MS every 50 minutes. A Hewlett-Packard 6890 Series II GC was used for sample introduction into the mass spectrometer. The GC program run from $45^{\circ} \mathrm{C}$ to a final temperature of $350^{\circ} \mathrm{C}$ at $6{ }^{\circ} \mathrm{C} / \mathrm{min}$ and held for $5 \mathrm{~min}$. The GC-MS 


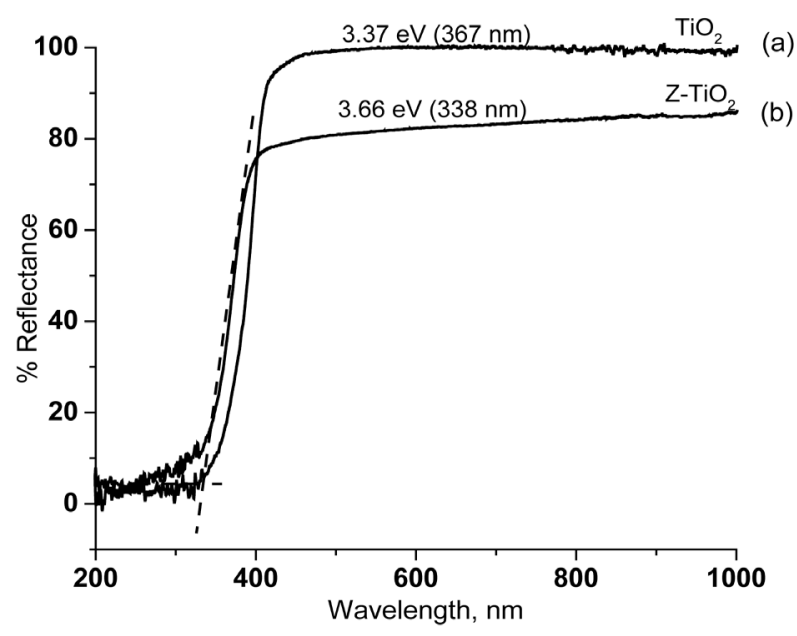

Figure 2. UV diffuse reflectance spectra of (a) $\mathrm{TiO}_{2}-\mathrm{P} 25$ (b) $\mathrm{Z}-\mathrm{TiO}_{2}$ photocatalysts.

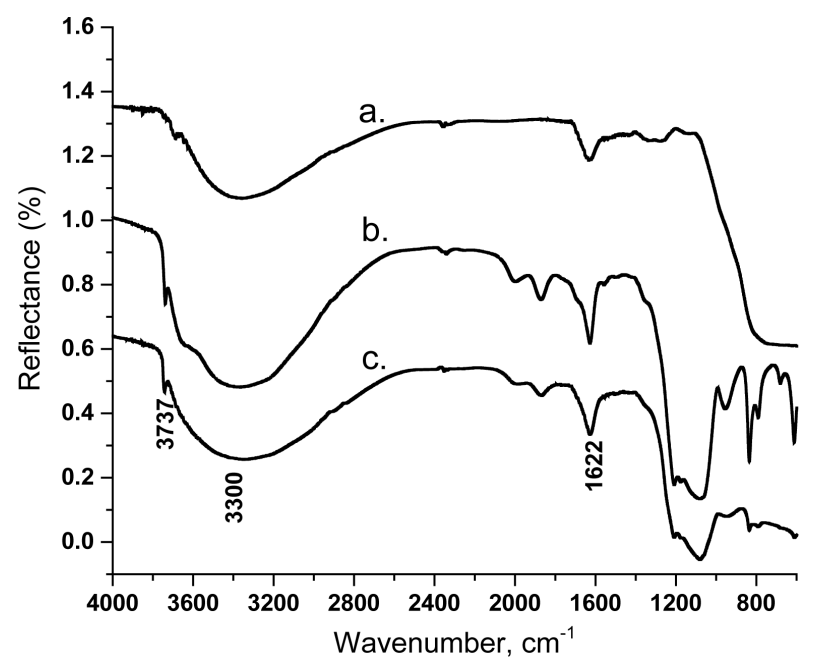

Figure 3. Infrared reflectance spectra of (a) $\mathrm{TiO}_{2}-\mathrm{P} 25$ (b) zeolite $\mathrm{CBY} 780$ and (c) $\mathrm{Z}-\mathrm{TiO}_{2}$ photocatalysts.

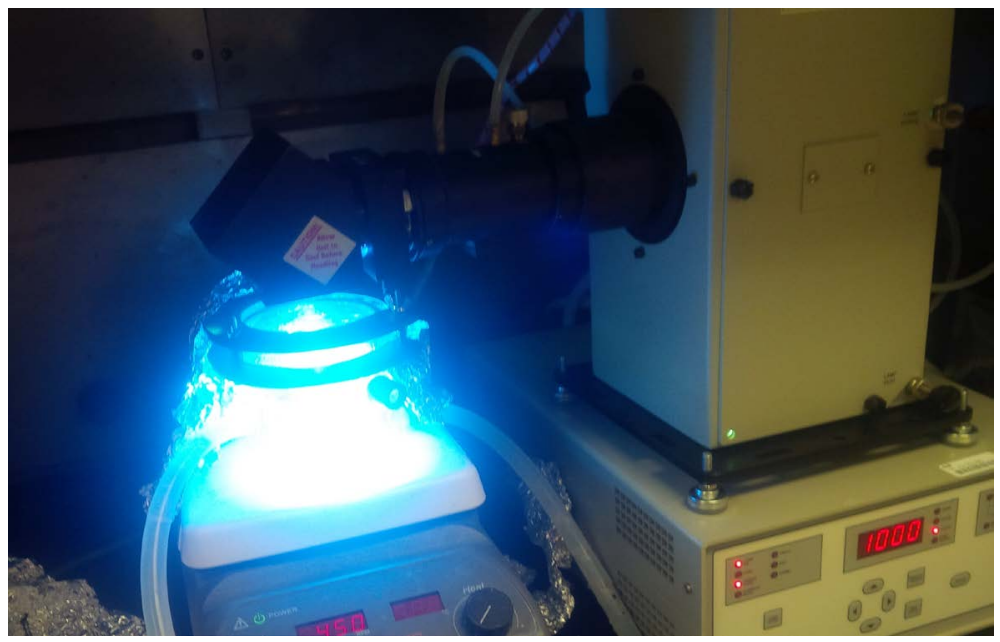

Figure 4. Set-up of the UV light source using $1000 \mathrm{~W} \mathrm{Hg}(\mathrm{Xe})$ lamp. 
transfer line was kept at $305^{\circ} \mathrm{C}$. A Hewlett-Packard Model 5973 mass-selective detector (MSD) in the electron ionization mode was used to obtain all mass spectra and analyzed by GC/MSD ChemStation version B.0403 using the Wiley $275 \mathrm{~L}$ database.

After 48 hours in the dark, the analysis of a headspace aliquot from the mixture of NA and $\mathrm{Z}-\mathrm{TiO}_{2}$ (Figure 5) shows atmospheric $\mathrm{CO}_{2}$ at 0.28 mins present in the sealed vessel, while naphthenic acid appears has a broad hump around 5 - 21 mins. The relative abundances of atmospheric $\mathrm{CO}_{2}$ and naphthenic acid stayed relatively constant during 48 hours of equilibration. The adsorption equilibration of NA and zeolite has been reported to initially occur by $\mathrm{H}$-bond interaction between the $-\mathrm{OH}$ in the $-\mathrm{COOH}$ group of the acid and the $\mathrm{O}$ atom of $\mathrm{Al}-\mathrm{O}$ and Si-O in clays [17]. The naphthenic acid hump consists of multiple components ranging in boiling point from $104^{\circ} \mathrm{C}$ to $334^{\circ} \mathrm{C}$. When UV light was illuminated on the mixture for 1 hour, the GC spectrum shows a $45 \%$ increase in the intensity of $\mathrm{CO}_{2}$ (Figure 6). After 3 hours of UV irradiation, there is a further $10 \%$ increase in the intensity of $\mathrm{CO}_{2}$ (Figure 7). By the $3^{\text {rd }}$ day of continued UV illumination, the $\mathrm{CO}_{2}$ intensity had increased up to a maximum of $93 \%$, while the NA intensity continued to decrease until no more could be detected from the gas phase (Figure 8). The rise in the concentrations of $\mathrm{CO}_{2}$ may indicate that the $\mathrm{COO}^{-}$groups in the naphthenic acids are converted to $\mathrm{CO}_{2}$. It has been reported that naphthenic acids containing multi-carboxylic groups are more susceptible to decarboxylation by photooxidation [18]. The lack of detectable naphthenic acids in the headspace aliquots after 3 days of UV light exposure on $\mathrm{NA}$ and $\mathrm{Z}-\mathrm{TiO}_{2}$ does not necessarily mean that all the acids in the mixture have been photooxidized. It is likely that there is some acid still adsorbed strongly to the surface of the catalyst that does not escape into the gas form. UV photooxidation of naphthenic acid was repeated

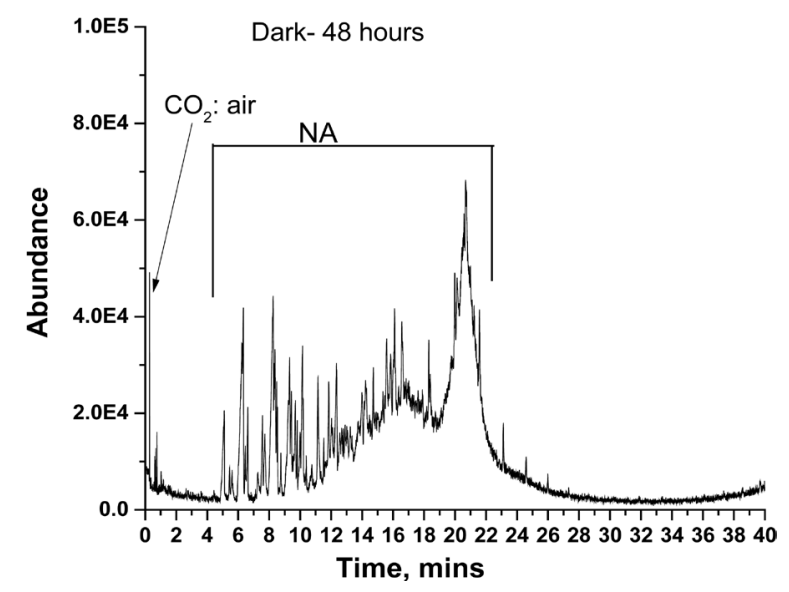

Figure 5. GC-MS spectra of head-space aliquots from mixture of $\mathrm{Z}-\mathrm{TiO}_{2}$ and naphthenic acid at $25^{\circ} \mathrm{C}$ kept in the dark for 48 hours.

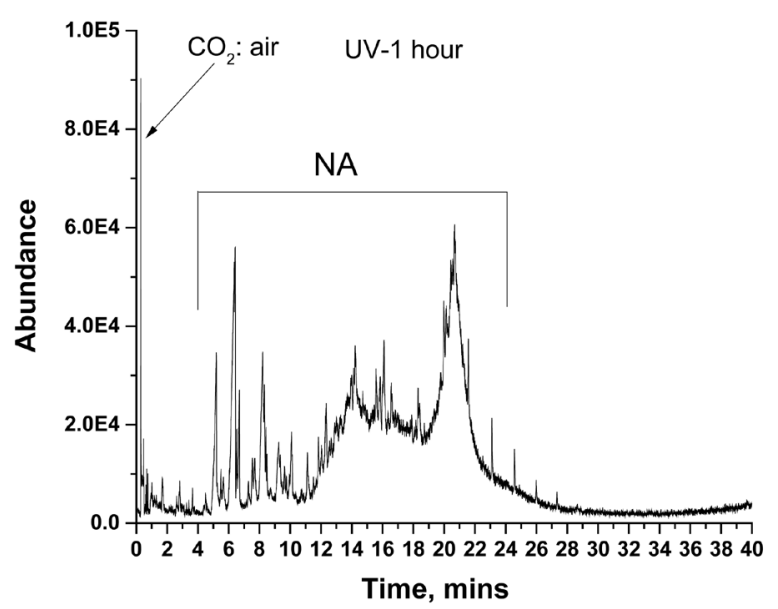

Figure 6. GC spectra of headspace gas from UV irradiation on $\mathrm{Z}-\mathrm{TiO}_{2}$ and naphthenic acid at $25^{\circ} \mathrm{C}$ for 1 hour. 


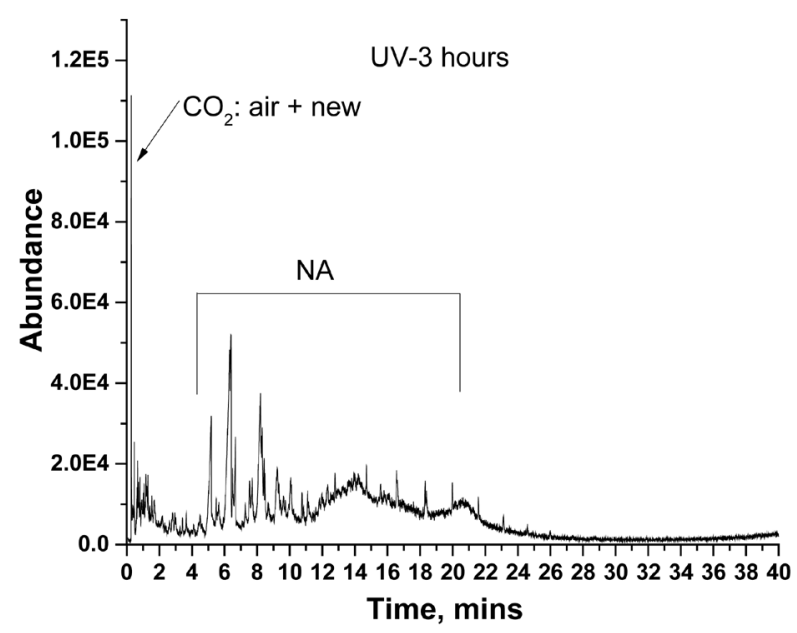

Figure 7. GC spectra of headspace gas from UV irradiation on $\mathrm{Z}-\mathrm{TiO}_{2}$ and naphthenic acid at $25^{\circ} \mathrm{C}$ for 3 hours. Abundance of $\mathrm{CO}_{2}$ has increased compared to dark conditions.

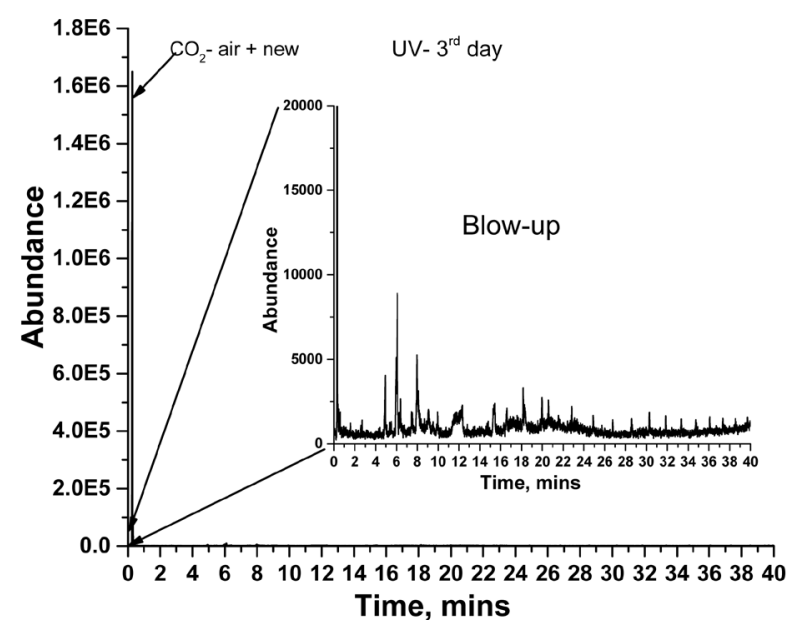

Figure 8. GC spectra of headspace gas from UV irradiation on $\mathrm{Z}-\mathrm{TiO}_{2}$ and naphthenic acid at $25^{\circ} \mathrm{C}$ over 3 days. Continued increase in $\mathrm{CO}_{2}$ intensity. Inset: expanded region of the GC showing decline in abundance of the acid.

several times and the same results were obtained showing that UV light plays a major role in reducing the amount of naphthenic acids in water.

An interesting observation was that the magnetic stir bars obtained from the mixture of naphthenic acid and $\mathrm{Z}-\mathrm{TiO}_{2}$ under UV light had a sticky and black oily substance (Figure 9). Even after heating the stir bars at $150^{\circ} \mathrm{C}$ for 2 hours, the oily substance was still present. On the other hand, magnetic stirs bars obtained when no light was shown on the NA and $\mathrm{Z}-\mathrm{TiO}_{2}$ mixture appeared very different. In this case, only a white solid presumably the catalyst was on the stir bars, and when heated at $150^{\circ} \mathrm{C}$ for 2 hours, the white solid dried up and could easily be brushed off. Work is underway to characterize these deposits on the stir bars.

Total Acidity Measurements: In order to determine if the decrease in the abundance of naphthenic acid from UV photocatalysis with $\mathrm{Z}-\mathrm{TiO}_{2}$ was due to the actual loss of $-\mathrm{COOH}$ groups, the total acidity of the mixtures were determined by thermometric titration, a method developed for finding the total acid number (TAN) of crude oil. Thermometric titrations involve an acid-base reaction where $0.1 \mathrm{~mol} / \mathrm{L} \mathrm{KOH}$ in isopropyl alcohol (IPA) is titrated with the acids until the endpoint is reached. The endpoint is recognized by the inflection of the titration curve and the concentration of TAN is reported as $\mathrm{mg} / \mathrm{KOH} / \mathrm{g}$ according to ASTM WK 26624. The TAN values were determined by an automated Metrohm 859 Titrotherm with Tiamo software. 
In a typical titration, $5 \mathrm{~g}$ of pure NA liquid was titrated with KOH/IPA (Figure 10) and the TAN value for the commercial acid was found to be $229 \mathrm{mgKOH} / \mathrm{g}$. The TAN of the diluted acid $(0.25 \%)$ dropped to $3.61 \mathrm{mg}$ $\mathrm{KOH} / \mathrm{g}$. TAN measurements were also performed for (a) the mixture of naphthenic acid and catalyst (b) filtrates, before and after light illumination. Table 2 shows that the TAN of diluted stock naphthenic acid and that of the mixture (dark) are in the same range, but the TAN for the mixture of acid and catalyst exposed to UV over 3 days decreased to $1.05 \mathrm{mg} \mathrm{KOH} / \mathrm{g}$. This change in TAN after UV photo-radiation on naphthenic acid and $\mathrm{Z}-\mathrm{TiO}_{2}$ suggests a reduction in the number of $-\mathrm{COOH}$ groups in the NA consistent with observations from GC-MS
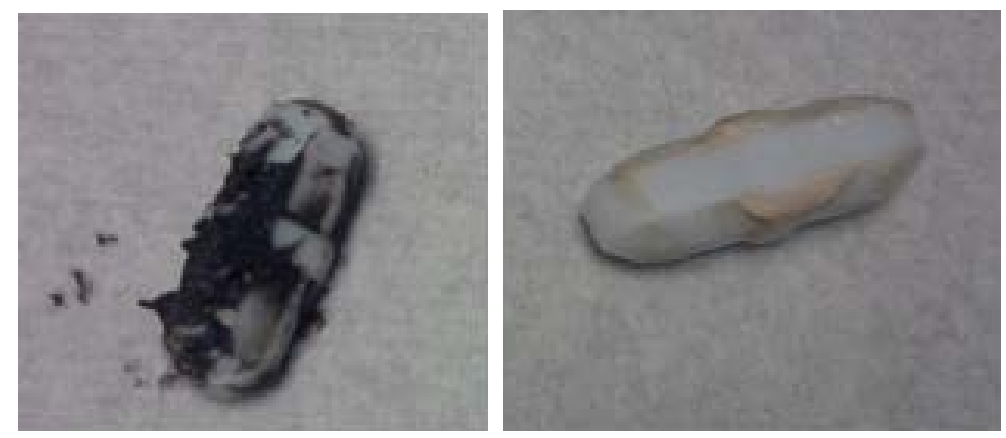

Figure 9. Appearance of stir bars from a mixture of $\mathrm{Z}-\mathrm{TiO}_{2}$ and naphthenic acid (Right) after exposure to UV light for 5 days and (Left) kept in dark for a week.

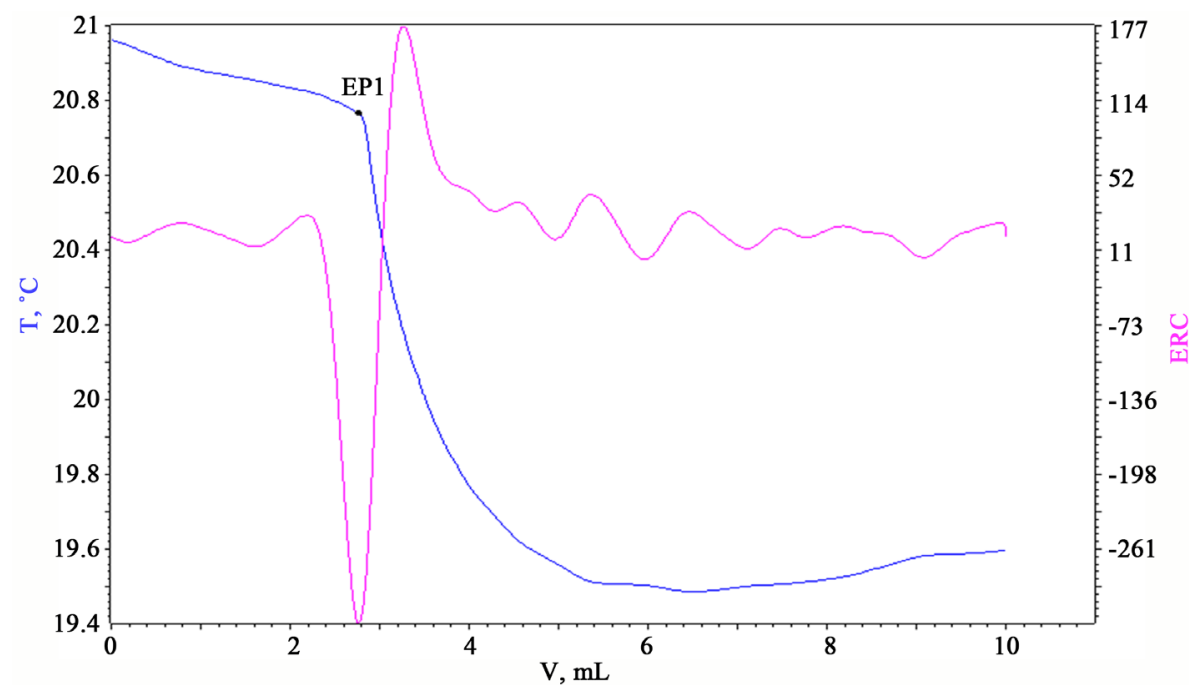

Figure 10. Thermometric titration curve of NA with KOH in IPA. The pink curve is the second derivative of the titration curve. EP1 is the end-point.

Table 2. TAN values for the various fractions from dark and UV conditions.

\begin{tabular}{ccc}
\hline & TAN, mgKOH/g & Endpoint, $\mathrm{mL}$ \\
\hline Pure naphthenic acid & 229.3 & 2.77 \\
Stock naphthenic acid & 3.611 & 4.42 \\
Mixture-Dark & 3.296 & 3.67 \\
Mixture-UV & 1.053 & 1.35 \\
Filtrate-Dark & 0.284 & 0.27 \\
Filtrate-UV & 0.130 & 0.24 \\
\hline
\end{tabular}


data, Figures 6-8. Total acid number measurements on the corresponding filtrates also showed a decrease in acidity from dark to UV exposed reactants. However, the TAN values for the filtrates are very low compared to those from the mixtures. Most likely, some of the oily acid was stuck on the catalyst surface and did not pass through the filter. As a precaution, thermometric titrations require a damping volume of titrant $\sim 0.20 \mathrm{~mL}$ to avoid falsely picking an endpoint that is actually noise incurred during the very initial start of titration. If the volume is exactly $0.20 \mathrm{~mL}$, it is likely that the true endpoint did not exceed the damping area. A higher sample volume should be used. Although, the endpoints of the filtrate solutions were very close to $0.20 \mathrm{~mL}$ regardless of sample size, the change in acidity mirrors the data obtained from mixtures as well as GC-MS.

\section{Conclusion}

In conclusion, UV photocatalysis of the multi-component naphthenic acid showed that the components of the acid were photodegraded to $\mathrm{CO}_{2}$. Although the amount of detectable naphthenic acid in the gas phase decreased dramatically over time, this is not an indication that all the naphthenic acid in solution had been oxidized. Acidity measurements on the reactant mixtures before and after UV irradiation provided further evidence of a decrease in acidity after UV treatment. The fact that a TAN value was obtained for UV treated mixture verified that some naphthenic acid is adsorbed on surface of catalysts and could not to be detected in the gas phase over time. Future efforts for the continuation of this project would involve a) conduct naphthenic acid photoreduction using a variety of UV and VIS-photocatalysts;(b) use real naphthenic acid containing water i.e. obtain oil sand processed water for such studies.

\section{Acknowledgements}

This work was supported by the Government of Canada's interdepartmental Program for Energy Research and Development (PERD), Program 1.1.3 Petroleum Conversion for Cleaner Air. The suggestions, comments and review by Patricia Arboleda were very helpful and appreciated.

\section{References}

[1] Clemente, J.S. and Fedorak, P.M. (2005) A Review of the Occurrence, Analyses, Toxicity, and Biodegradation of Naphthenic Acids. Chemosphere, 60, 585-600. http://dx.doi.org/10.1016/j.chemosphere.2005.02.065

[2] Kamaluddin, M. and Zwiazek, J.J. (2002) Naphthenic Acids Inhibit Root Water Transport, Gas Exchange and Leaf Growth in Aspen (Populus Tremuloides) Seedlings. Tree Physiology, 22, 1265-1270. http://dx.doi.org/10.1093/treephys/22.17.1265

[3] Biryukova, O.V., Fedorak, P.M. and Quideau, S.A. (2007) Biodegradation of Naphthenic Acids by Rhizosphere Microorganisms. Chemosphere, 67, 2058-2064. http://dx.doi.org/10.1016/j.chemosphere.2006.11.063

[4] Johnson, R.J., Smith, B.E., Sutton, P.A., McGenity, T.J., Rowland, S.J. and Whitby, C. (2011) Microbial Biodegradation of Aromatic Alkanoic Naphthenic Acids is Affected by the Degree of AlkylSide Chain Branching. ISME Journal, 5, 486-496. http://dx.doi.org/10.1038/ismej.2010.146

[5] Scott, A.C., Mackinnon, M.D. and Fedorak, P.M. (2005) Naphthenic Acids in Athabasca Oil Sands Tailings Waters Are Less Biodegradable than Commercial Naphthenic Acids. Environmental Science Technology, 39, 8388-8394. http://dx.doi.org/10.1021/es051003k

[6] McKenzie, N., Yue, S., Liu, X., Ramsay, B.A. and Ramsay, J.A. (2014) Biodegradation of Naphthenic Acids in Oils Sands Process Waters in an Immobilized Soil/Sediment Bioreactor. Chemosphere, 109, 164-172. http://dx.doi.org/10.1016/j.chemosphere.2014.02.001

[7] Headley, J.V., Du, J.L., Peru, K.M. and McMartin, D.W. (2009) Electrospray Ionization Mass Spectrometry of the Photodegradation of Naphthenic Acids Mixtures Irradiated with Titanium Dioxide. Journal of Environmental Science and Health, Part A: Toxic/Hazardous Substances and Environmental Engineering, 44, 591-597. http://dx.doi.org/10.1080/10934520902784625

[8] McMartin, D.W., Headley, J.V., Friesen, D.A., Peru, K.M. and Gillies, J.A. (2004) Photolysis of Naphthenic Acids in Natural Surface Water. Journal of Environmental Science and Health, Part A: Toxic/Hazardous Substances and Environmental Engineering, 39, 1361-1383. http://dx.doi.org/10.1081/ESE-120037839

[9] Mishra, S., Meda, V., Dalai, A.K., McMartin, D.W., Headley, J.V. and Peru, K.M. (2010) Photocatalysis of Naphthenic Acids in Water. Journal of Water Resource and Protection, 2, 644-650. http://dx.doi.org/10.4236/jwarp.2010.27074 
[10] Allen, E.W. (2008) Process Water Treatment in Canada’s Oil Sands Industry: II. A Review of Emerging Technologies. Journal of Environmental Engineering and Science, 7, 499-524. http://dx.doi.org/10.1139/S08-020

[11] Bahnemann, D. (2004) Photocatalytic Water Treatment: Solar Energy Applications. Solar Energy, 77, 445-459. http://dx.doi.org/10.1016/j.solener.2004.03.031

[12] Kalebaila, K.K. and Klabunde, K.J. (2010) An Inorganic Oxide $\mathrm{TiO}_{2}-\mathrm{SiO}_{2}$-Mn Aerogel for Visible-Light Induced Air Purification. In: Erickson, L.E., Koodali, R.T. and Richards, R.M., Nanoscale Materials in Chemistry: Environmental Applications, American Chemical Society, Washington DC, 207-223.

[13] Zhang, W., Zou, L. and Wang, L. (2009) Photocatalytic $\mathrm{TiO}_{2} /$ Adsorbent Nanocomposites Prepared via Wet Chemical Impregnation for Wastewater Treatment: A Review. Applied Catalysis A: General, 371, 1-9. http://dx.doi.org/10.1016/j.apcata.2009.09.038

[14] Webb, P.A. and Orr, C. (1997) Analytical Methods in Fine Particle Technology. Micromeritics Instrument Corp, Norcross.

[15] Tahir, D., Kwon, H.L., Shin, H.C., Oh, S.K., Kang, H.J., Heo, S., et al. (2010) Electronic and Optical Properties of $\mathrm{Al}_{2} \mathrm{O}_{3} / \mathrm{SiO}_{2}$ Thin Films Grown on Si Substrate. Journal of Physics D: Applied Physics, 43, 255301-255400.

[16] Halasz, I., Agarwal, M., Marcus, B. and Cormier, W.E. (2005) Molecular Spectra and Polarity Sieving of Aluminum Deficient Hydrophobic H-Y Zeolites. Microporous and Mesoporous Materials, 84, 318-331. http://dx.doi.org/10.1016/j.micromeso.2005.05.040

[17] Zou, L., Han, B., Yan, H., Kasperski, K.L., Xu, Y. and Hepler, L.G. (1997) Enthalpy of Adsorption and Isotherms for Adsorption of Naphthenic Acid onto Clays. Journal of Colloid and Interface Science, 190, 472-475. http://dx.doi.org/10.1006/jcis.1997.4898

[18] Frank, R.A., Kavanagh, R., Burnison, B.K., Arsenault, G., Headley, J.V., Peru, K.M., Van Der Kraak, G. and Solomon, K.R. (2008) Toxicity Assessment of Collected Fractions from an Extracted Naphthenic Acid Mixture. Chemosphere, 72, 1309-1314. http://dx.doi.org/10.1016/j.chemosphere.2008.04.078 
Scientific Research Publishing (SCIRP) is one of the largest Open Access journal publishers. It is currently publishing more than 200 open access, online, peer-reviewed journals covering a wide range of academic disciplines. SCIRP serves the worldwide academic communities and contributes to the progress and application of science with its publication.

Other selected journals from SCIRP are listed as below. Submit your manuscript to us via either submit@scirp.org or Online Submission Portal.
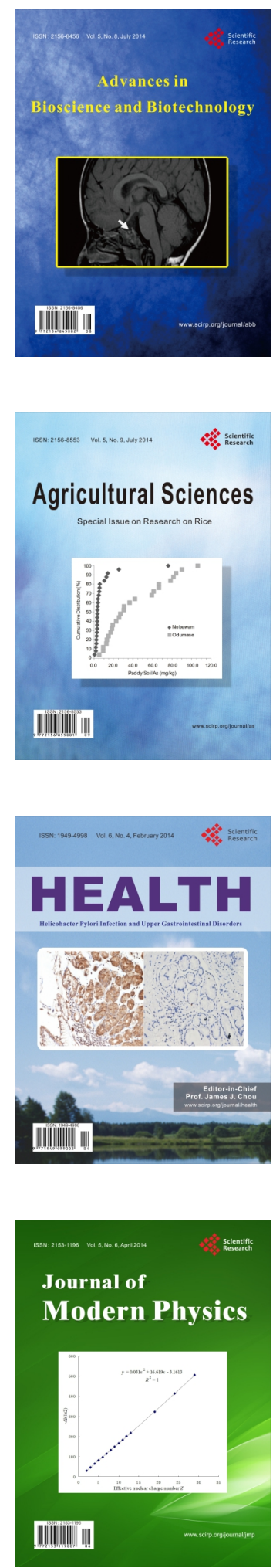
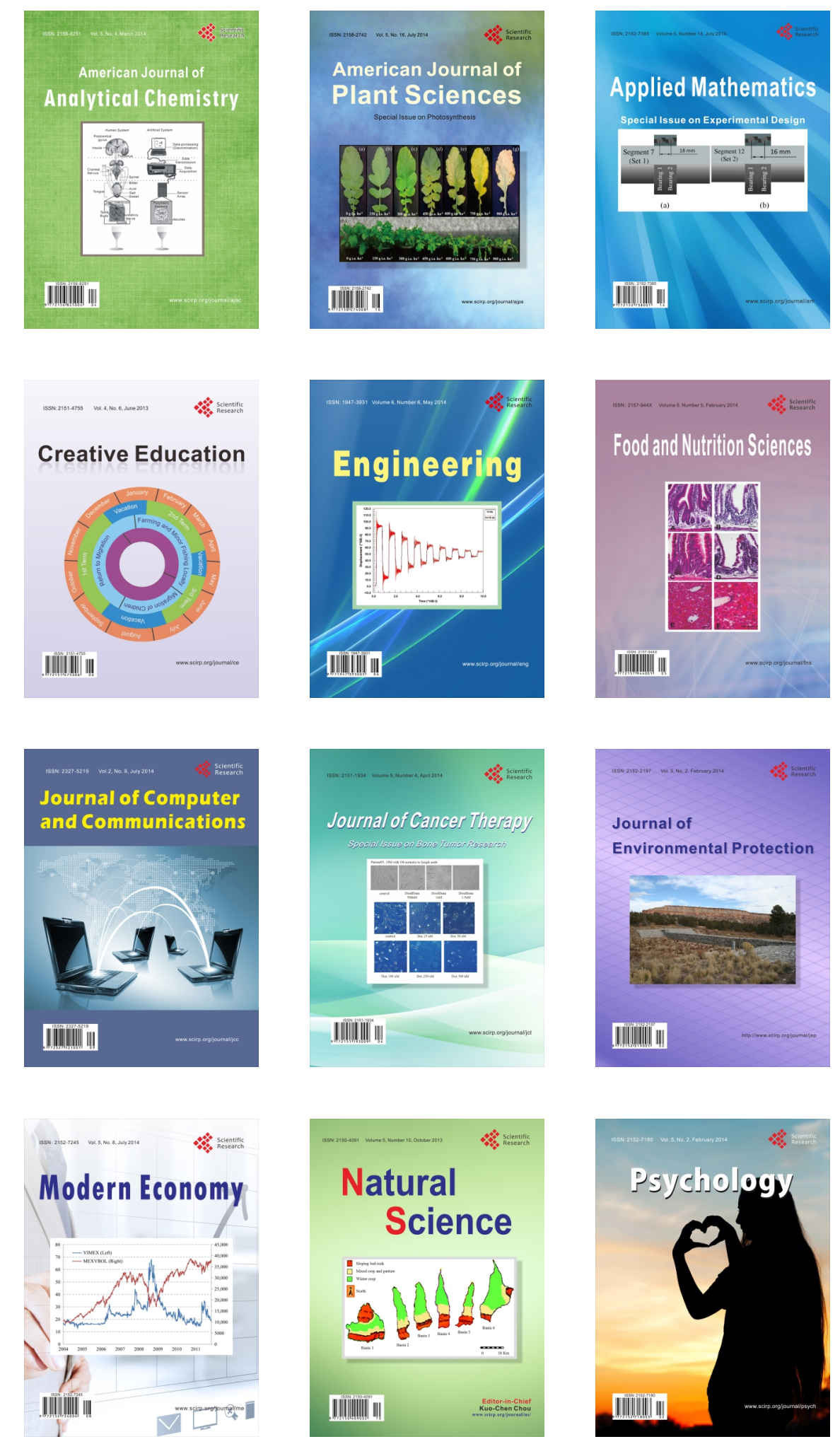